\title{
Germline mutations in a polycytosine repeat of the hMSH6 gene in Korean hereditary nonpolyposis colorectal cancer
}

\begin{abstract}
Somatic mutations within a mononucleotide repeat sequence present in the $h M S H 6$ and $h M S H 3$ coding regions have been frequently observed in various human cancer tissues and cell lines showing genomic instability. However, relatively few germline mutations of the repeat sequence have been identified. Two germline mutations in the $h M S H 6$ region have been reported in hereditary nonpolyposis colorectal cancer (HNPCC); however, no germline mutations in the $h M S H 3$ gene have been reported yet. To investigate genetic alterations within an $8 \mathrm{bp}$ polycytosine repeat of the $h M S H 6$ gene and an 8-bp polyadenine repeat of the $h M S H 3$ gene, we amplified the mononucleotide repeat sequences of 35 HNPCC patients, 44 patients suspected of having HNPCC who did not fulfill the criteria of the International Collaborative Group on HNPCC, and 45 patients with sporadic early-onset colorectal cancer who developed colorectal cancer before the age of 40 years without any family history of colorectal cancer. Genetic alteration of the repeat sequence of the $h M S H 3$ gene was not observed, whereas germline frameshift mutations (one C insertion) in the $h M S H 6$ gene were found in two of the 44 suspected HNPCC patients in whom germline mutations of $h M S H 2$ or $h M L H 1$ had not been detected. An identical frameshift mutation was also observed in another affected member of a suspected HNPCC family. These results suggest that the mutation of $h M S H 6$ is responsible for tumorigenesis in minor groups of suspected HNPCC patients.
\end{abstract}

Key words Germline mutation . HNPCC · hMSH6 . hMSH3

K.-H. Shin · J.-L. Ku · J.-G. Park ( $\varangle)$

Korean Hereditary Tumor Registry, Laboratory of Cell Biology,

Cancer Research Center and Cancer Research Institute,

Seoul National University College of Medicine, 28 Yongon-dong,

Chongno-gu, Seoul 110-744, Korea

Tel. +82-2-760-3380; Fax +82-2-742-4727

e-mail: jgpark@plaza.snu.ac.kr

\section{Introduction}

Hereditary nonpolyposis colorectal cancer (HNPCC) is the most common hereditary condition predisposing patients to the development of colorectal cancer. Germline mutations in genes of the mismatch repair (MMR) system, namely $h M S H 2, h M L H 1, h P M S 1$, and $h P M S 2$, have been identified in patients with HNPCC (Fishel et al. 1993; Bronner et al. 1994; Liu et al. 1994; Nicolaides et al. 1994; Han et al. 1996). Defective MMR is associated with alterations in microsatellite sequences, indicating genomic instability.

Two other MMR genes, $h M S H 6$ (also known as GTBP) and $h M S H 3$, which are also involved in the MMR pathway have been cloned as bacterial mutS homologs (Drummond et al. 1995; Palombo et al. 1995). Somatic mutations in the $h M S H 6$ and $h M S H 3$ genes, especially at mononucleotide repeat sequences, have been observed in HNPCC, sporadic colorectal, and gastric carcinomas showing genomic instability (Akiyama et al. 1997b; Yamamoto et al. 1997; Yin et al. 1997). Most of the mutations found were additions or deletions of the mononucleotide repeat sequences present in the $h M S H 3$ and $h M S H 6$ coding regions. This observation suggested that these genes may be the target genes of the genomic instability in tumorigenesis. Recently, germline mutations in $h M S H 6$ were reported (Akiyama et al. 1997b; Miyaki et al. 1997). Our previous studies demonstrating a relatively low incidence of mutation in the $h M S H 2$ and hMLH1 genes in HNPCC patients have indicated the possibility of genetic alterations in other MMR genes (Han et al. 1996; Yuan et al. 1998).

Therefore, to clarify whether or not germline mutation in the repeat sequences of $h M S H 6$ and $h M S H 3$ is implicated in tumorigenesis, we screened 35 HNPCC patients satisfying the International Collaborative Group on HNPCC (ICG-HNPCC) criteria, and 44 suspected HNPCC patients. We previously proposed the term "suspected HNPCC" for families who do not fulfill the ICG-HNPCC criteria but in whom a genetic basis for colon cancer is strongly suspected (Han et al. 1996; Yuan et al. 1998). These families were registered according to the suggested criteria: 
Table 1 Frequency of germline mutations in the $h M S H 6, h M S H 3, h M S H 2$, and $h M L H 1$ genes

\begin{tabular}{|c|c|c|c|c|c|}
\hline Group & $h M S H 6^{\mathrm{a}}$ & $h M S H 3^{\mathrm{a}}$ & $h M S H 2^{\mathrm{b}}$ & $h M L H 1^{\mathrm{b}}$ & Total \\
\hline ICG-HNPCC & $0 / 35(0 \%)$ & $0 / 35(0 \%)$ & $0 / 35^{\mathrm{c}}(0 \%)$ & $11 / 35^{\mathrm{c}}(31.4 \%)$ & $11 / 35^{\mathrm{c}}(31.4 \%)$ \\
\hline Suspected HNPCC & $2 / 44(4.5 \%)$ & $0 / 44(0 \%)$ & $2 / 44^{\mathrm{d}}(4.5 \%)$ & $7 / 44^{\mathrm{d}}(15.9 \%)$ & $11 / 44(24.9 \%)$ \\
\hline Early onset colorectal cancer & $0 / 45(0 \%)$ & $0 / 45(0 \%)$ & $1 / 45^{\mathrm{e}}(2.2 \%)$ & $0 / 45^{\mathrm{e}}(0 \%)$ & $1 / 45(2.2 \%)$ \\
\hline
\end{tabular}

ICG-HNPCC, International Collaborative Group on Hereditary Nonpolyposis Colorectal Cancer

${ }^{a}$ Polycytosine and polyadenine repeat sequences present in coding region of, respectively, $h M S H 6$ and $h M S H 3$, were examined by

polymerase chain reaction - single-strand conformation polymorphism (PCR-SSCP) and sequencing analysis

${ }^{b}$ All exons of the gene were examined by PCR-SSCP and sequencing analysis

${ }^{c}$ Twenty-five cases were previously reported (Han et al. 1996)

${ }^{\mathrm{d}}$ Thirty-one cases were previously reported (Han et al. 1996; Yuan et al. 1998)

${ }^{\mathrm{e}}$ Forty-five cases were previously reported (Han et al. 1996; Yuan et al. 1998)

(1) vertical transmission of colorectal cancer or at least two siblings affected with colorectal cancer in a family; (2) development of multiple colorectal tumors or at least one colorectal cancer diagnosed before the age of 50 years. A $20 \%$ mutational frequency of the $h M S H 2$ and $h M L H 1$ genes was identified in our study of 44 suspected HNPCC patients, including the previous reported 31 suspected HNPCC patients (Table 1). Forty-five early-onset colorectal cancer patients who developed colorectal cancer before the age of 40 years without any family history of colorectal cancer were also examined.

\section{Materials and methods}

Subjects and DNA isolation from blood samples

Including the previously reported samples, 35 HNPCC, 44 suspected HNPCC, and 45 sporadic early-onset colorectal cancer patients registered in the Korean Hereditary Colorectal Cancer Registry were used in this study (Han et al. 1996; Yuan et al. 1998). Between $20 \mathrm{ml}$ and $30 \mathrm{ml}$ of peripheral blood from each patient was used to prepare genomic DNA from white blood cells, as described elsewhere (Blin et al. 1976).

Analysis of the mononucleotide repeat sequences in $h M S H 6$ and $h M S H 3$

We analyzed frameshift mutations in the repeat sequences by modified polymerase chair reaction - single-strand conformation polymorphism (PCR-SSCP). The PCR primers were sense (5'-TGA CTG ATA CTT CTA CCA GC-3') and antisense (5'-AAC ATT TGT TCC TCA CCT GC-3') for the 8-bp polyadenine repeat in exon 7 of the $h M S H 3$ gene and sense (5'-GGG TGA TGG TCC TAT GTG TC$3^{\prime}$ ) and antisense (5'-CGT AAT GCA AGG ATG GCG T$3^{\prime}$ ) for the 8-bp polycytosine repeat in exon 5 of the $h M S H 6$ gene. The repeat sequences were amplified from $100 \mathrm{ng}$ of genomic DNA using the sense primer of each gene labeled with $\left[\gamma^{32} \mathrm{P}\right] \mathrm{dATP}$ using T4 polynucleotide kinase and the unlabeled antisense primer of each gene. The PCR condition consisted of 35 cycles at $95^{\circ} \mathrm{C}$ for $30 \mathrm{~s}, 45^{\circ} \mathrm{C}$ for $1 \mathrm{~min}$, and $70^{\circ} \mathrm{C}$ for $1 \mathrm{~min}$. The PCR products were denatured, separated on $7 \%$ polyacrylamide gels on $60 \mathrm{~W}$ constant, and visualized by autoradiography.

DNA sequencing analysis

When abnormal patterns were detected by PCR-SSCP analysis, the PCR products were purified with QIAquick PCR purification kit (Qiagen, Inc., Chatsworth, CA, USA) and then sequenced directly with a Taq dideoxy terminator cycle sequencing kit on an ABI 377 automatic DNA sequencer (Perkin-Elmer, Foster city, CA, USA).

\section{Results and discussion}

PCR-SSCP analysis of the mononucleotide repeat sequence in $h M S H 3$ did not detect an abnormal band pattern. However, the analysis of the $h M S H 6$ gene revealed abnormal bands from the DNAs of two suspected HNPCC patients (SNU-H1005 and SNU-H1047) in which germline mutations of $h M S H 2$ and hMLH1 could not be detected (Figs 1a and 2a). In the SNU-H1005 and the SNU-H1047 patients, subsequent sequencing analysis of the $h M S H 6$ gene revealed one C insertion at codons 1085-1087, predicting a premature stop codon in codon 1092 (Figs 1c and 2b). This germline mutation was identical to the previously reported germline mutation found in an HNPCC-like patient (Akiyama et al. 1997a). Patient SNU-H1005 was diagnosed as having rectal cancer at the age of 37 years. Although the SNU-H1005 family did not meet the ICGHNPCC criteria, two of the seven siblings were diagnosed as having colorectal cancer (also, their father had died of gastric cancer). Because the blood of the brother of the affected family member was not available, we could not examine the mutation at the repeat sequence. However, the mutation was not detected in the normal members (his two sisters). Patient SNU-H1047 had rectal cancer at 37 years of age, and his mother was also diagnosed with colorectal cancer at 67 years of age. We tested for the mutation at the polycytosine repeat sequence in $h M S H 6$ from the genomic DNAs of his mother and two normal family members (his daughter and his mother's sister). An identical frameshift mutation to that found in SNU-H1047 was detected only in the DNA of his mother (data not shown). Since germline 
Fig. 1 Alteration in the polycytosine repeat sequence of hMSH6. a PCR-SSCP analysis of the repeat sequence of $h M S H 6$. An abnormal band pattern was detected in normal cells from patient SNU-H1005. b Sequencing analysis of the repeat sequence of hMSH6 from normal DNA. c Sequencing analysis of the repeat sequence of $h M S H 6$ in SNU$\mathrm{H} 1005$. A heterozygous one-C insertion was found
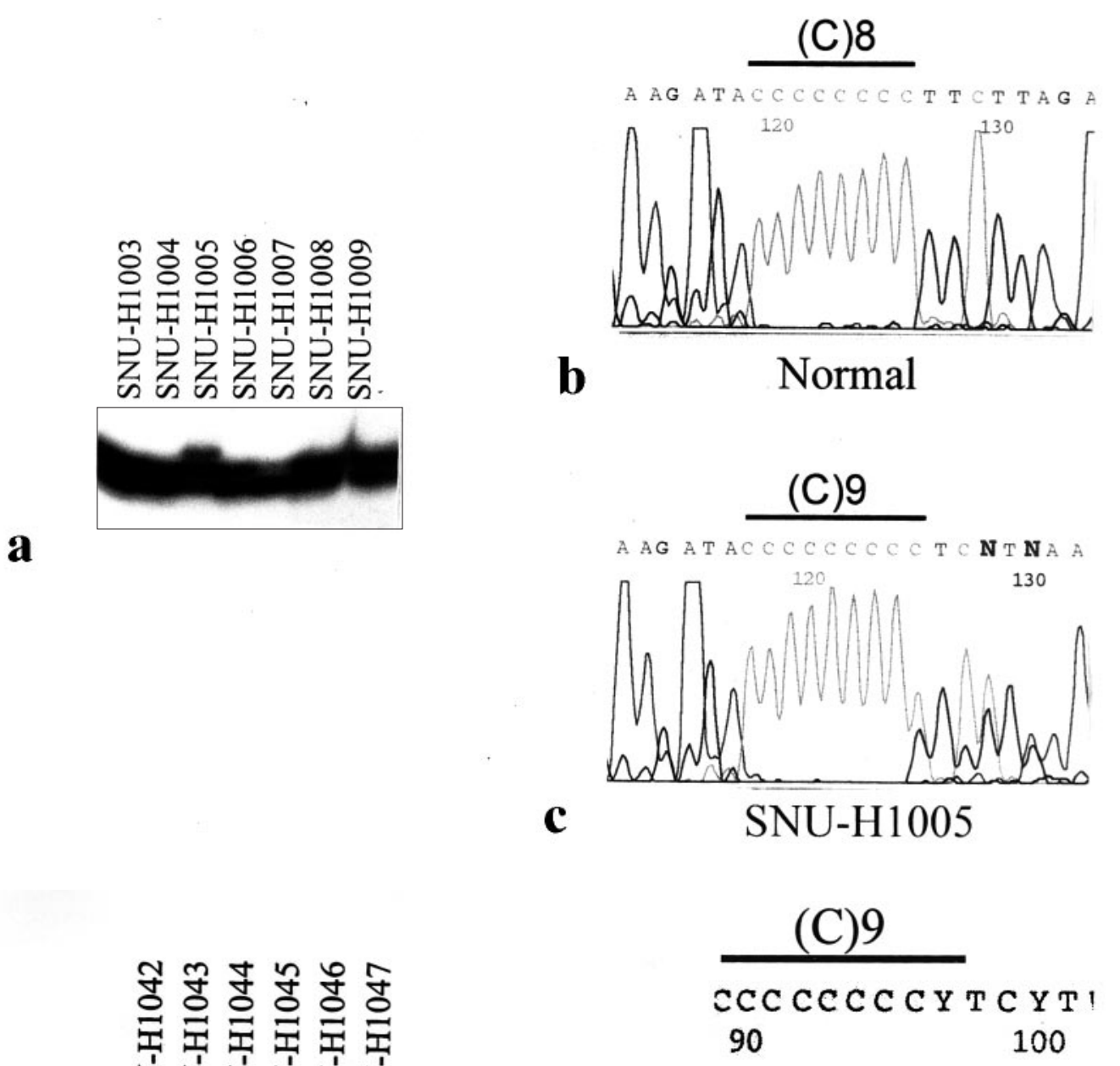

Fig. 2 a PCR-SSCP analysis of the repeat sequence of $h M S H 6$. An abnormal band pattern was detected in normal cells from patient SNU-H1047. b Sequencing analysis of the repeat sequence of hMSH6 in SNU-H1047. A heterozygous one-C insertion was found
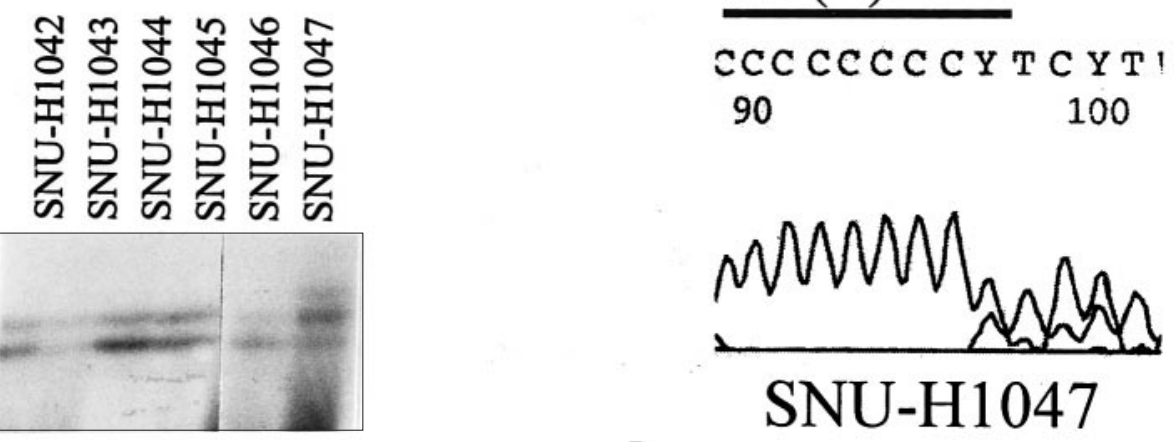

b mutations in the $h M S H 2$ and $h M L H 1$ genes were not detected, and a functionally inactive mutation of $h M S H 6$ was found only in the affected family members, we concluded that frameshift mutation of the hMSH6 gene is pathogenic in the tumorigenesis of these families.

Although mutation screening was performed in a very limited area of the $h M S H 6$ gene, the mutation frequency $(4.5 \%)$ of the gene was the same as that of $h M S H 2$ in which all the exons were examined by PCR-SSCP analysis in 44 suspected HNPCC patients (Table 1). Since a germline mutation outside the repeat sequence of the hMSH6 gene was found in an HNPCC kindred (Miyaki et al. 1997), the entire coding sequence of the $h M S H 6$ gene is under investigation in our samples. Our results suggest that genetic testing for the $h M S H 6$ gene should be required in HNPCC and suspected HNPCC patients without germline mutations of the $h M S H 2$ and $h M L H 1$ genes.
Acknowledgments This work was supported by grants from the 1997 Good Health R \& D Project, the Ministry of Health and Welfare of the Republic of Korea, and from the Korea Science and Engineering Foundation (KOSEF-CRC97-8) through the Cancer Research Center at Seoul National University.

\section{References}

Akiyama Y, Sato H, Yamada T, Nagasaki H, Tsuchiya A, Abe R, Yuasa Y (1997a) Germ-line mutation of the $h M S H 6 / G T B P$ gene in an atypical hereditary nonpolyposis colorectal cancer kindred. Cancer Res 57: 3920-3923

Akiyama Y, Tsubouchi N, Yuasa Y (1997b) Frequent somatic mutations of $h M S H 3$ with reference to microsatellite instability in hereditary nonpolyposis colorectal cancers. Biochem Biophys Res Commun 236: 248-252

Blin N, Stafford DM (1976) A general method for isolation for high molecular weight DNA from eukaryotes. Nucleic Acids Res 3: 23032308 
Bronner CE, Baker SM, Morrison PT, Warren G, Smith LG, Lescoe MK, Kane M, Earabino C, Lipford J, Lindblom A, Tannergard P, Bollag RJ, Godwin AR, Ward DC, Nordenskjold M, Fishel R, Kolodner R, Liskay RM (1994) Mutation in the DNA mismatch repair gene homologue $h M L H 1$ is associated with hereditary nonpolyposis colon cancer. Nature 368: 258-261

Drummond JT, Li G-M, Longley MJ, Modrich P (1995) Isolation of an hMSH2-p160 heterodimer that restores DNA mismatch repair to tumor cells. Science 268: 1909-1912

Fishel R, Lescoe MK, Rao MR, Copeland NG, Jenkins NA, Garber J, Kane M, Kolodner R (1993) The human mutator gene homolog $\mathrm{MSH} 2$ and its association with hereditary nonpolyposis colon cancer. Cell 75: 1027-1038

Han H-J, Yuan Y, Ku J-L, Oh J-H, Won Y-J, Kang K-J, Kim KY, Kim S, Kim CY, Kim J-P, Oh N-G, Lee KH, Choe KJ, Nakamura Y, Park J-G (1996) Germline mutations of $h M L H 1$ and $h M S H 2$ genes in Korean hereditary nonpolyosis colorectal cancer. J Natl Cancer Inst 88: 1317-1319

Liu B, Parson RE, Hamilton SR, Petersoen GM, Lynch HT, Watson P, Markowitz S, Willson JK, Green J, de la Chapelle A, Kinzler KW, Vogelstein B (1994) hMSH2 mutations in hereditary nonpolyposis colorectal cancer kindreds. Cancer Res 54: 4590-4594

Miyaki M, Konishi M, Tanaka K, Kikuchi-Yanoshita R, Muraoka M, Yasuno M, Igari T, Koike M, Chiba M, Mori T (1997) Germline mutation of $\mathrm{MSH6}$ as the cause of hereditary nonpolyposis colorectal cancer. Nat Genet 17: 271-272

Nicolaides NC, Papadopoulos N, Liu B, Wei YF, Carter KC, Ruben SM, Rosen CA, Haseltine WA, Fleischmann RD, Fraser CM, Adams MD, Venter JC, Dunlop MG, Hamilton SR, Petersen GM, de al Chapella A, Vogestein B, Kinzler KW (1994) Mutations of two $P M S$ homologues in hereditary nonpolyposis colon cancer. Nature 371: $75-80$

Palombo F, Gallinari P, Iaccarino I, Lettieri T, Hughes M, D'Arrigo A, Truong O, Hsuan JJ, Jiricny J (1995) GTBP, a 160-kilodalton protein essential for mismatch-binding activity in human cells. Science 268: 1912-1914

Yamamoto H, Sawai H, Perucho M (1997) Frameshift somatic mutations in gastrointestinal cancer of the microsatellite mutator phenotype. Cancer Res 57: 4420-4426

Yin J, Kong D, Wang S, Zou T-T, Souza RF, Smolinski KN, Lynch PM, Hamilton SR, Sugimura H, Powell SM, Young J, Abraham JM, Meltzer SJ (1997) Mutation of $h M S H 3$ and $h M S H 6$ mismatch repair genes in genetically unstable human colorectal and gastric carcinomas. Hum Mutation 10: 474-478

Yuan Y, Han H-J, Zheng S, Park J-G (1998) Germline mutations of $h M L H 1$ and $h M S H 2$ genes in patients with suspected hereditary nonpolyposis colorectal cancer and sporadic early-onset colorectal cancer. Dis Colon Rectum 41: 434-440 